\title{
Erratum to: Benchmarks for ethically credible partnerships between industry and academic health centers: beyond disclosure of financial conflicts of interest
}

Eric M. Meslin ${ }^{1 *}$, Joshua B. Rager ${ }^{1}$, Peter H. Schwartz ${ }^{1}$, Kimberly A. Quaid ${ }^{1}$, Margaret M. Gaffney ${ }^{1}$, Jon Duke ${ }^{2}$ and William M. Tierney ${ }^{2}$

\section{Erratum to: Clin Trans Med (2015) 4:36 \\ DOI 10.1186/s40169-015-0077-y}

Following publication of the original version of this article in Clinical and Translational Medicine [1] it was brought to our attention that the name of one author was spelled incorrectly. The name of author William M. Tierney was incorrectly spelled as William $\mathrm{H}$. Tierney. The original article has been updated with the correct information. We apologize for the inconvenience.

\section{Author details}

${ }^{1}$ Indiana University Center for Bioethics, 410 West 10th Street, Indianapolis, IN 46202, USA. ${ }^{2}$ Regenstrief Institute Inc., 410 West 10th Street, Indianapolis, IN 46202, USA.

The online version of the original article can be found under doi:10.1186/s40169-015-0077-y.

Received: 4 January 2016 Accepted: 18 January 2016

Published online: 29 January 2016

\section{Reference}

1. Meslin et al (2015) Benchmarks for ethically credible partnerships

between industry and academic health centers: beyond disclosure of

financial conflicts of interest. Clin Trans Med 4:36

\footnotetext{
*Correspondence: emeslin@iu.edu

${ }^{1}$ Indiana University Center for Bioethics, 410 West 10th Street,

Indianapolis, IN 46202, USA

Full list of author information is available at the end of the article
}

\section{Springer}

(C) 2016 Meslin et al. This article is distributed under the terms of the Creative Commons Attribution 4.0 International License (http://creativecommons.org/licenses/by/4.0/, which permits unrestricted use, distribution, and reproduction in any medium, provided you give appropriate credit to the original author(s) and the source, provide a link to the Creative Commons license, and indicate if changes were made 